\title{
Article
}

\section{A Comprehensive Analysis of Groundwater Quality in The Barnett Shale Region}

Zacariah Louis Hildenbrand, Doug D Carlton, Brian Fontenot, Jesse M. Meik, Jayme Walton, Josh Taylor, Jonathan Thacker, Stephanie Korlie, C. Phillip Shelor, Drew Henderson, Akinde Florence Kadjo, Corey Roelke, Paul F. Hudak, Taylour Burton, Hanadi S. Rifai, and Kevin A. Schug

Environ. Sci. Technol., Just Accepted Manuscript • DOI: 10.1021/acs.est.5b01526 • Publication Date (Web): 16 Jun 2015

Downloaded from http://pubs.acs.org on June 17, 2015

\section{Just Accepted}

"Just Accepted" manuscripts have been peer-reviewed and accepted for publication. They are posted online prior to technical editing, formatting for publication and author proofing. The American Chemical Society provides "Just Accepted" as a free service to the research community to expedite the dissemination of scientific material as soon as possible after acceptance. "Just Accepted" manuscripts appear in full in PDF format accompanied by an HTML abstract. "Just Accepted" manuscripts have been fully peer reviewed, but should not be considered the official version of record. They are accessible to all readers and citable by the Digital Object Identifier (DOI@). "Just Accepted" is an optional service offered to authors. Therefore, the "Just Accepted" Web site may not include all articles that will be published in the journal. After a manuscript is technically edited and formatted, it will be removed from the "Just Accepted" Web site and published as an ASAP article. Note that technical editing may introduce minor changes to the manuscript text and/or graphics which could affect content, and all legal disclaimers and ethical guidelines that apply to the journal pertain. ACS cannot be held responsible for errors or consequences arising from the use of information contained in these "Just Accepted" manuscripts. 

Barnett Shale Region

\section{AUTHOR NAMES:}

Zacariah Louis Hildenbrand, ${ }^{a, b, t,{ }^{*}}$ Doug D. Carlton Jr., ${ }^{b, c, \dagger}$ Brian Fontenot, ${ }^{b,} \|, \dagger$ Jesse M. Meik, ${ }^{b, d, ~}{ }^{\dagger}$ Jayme Walton, ${ }^{b, e}$ Josh Taylor, ${ }^{a}$ Jonathan Thacker, ${ }^{c}$ Stephanie Korlie, ${ }^{c}$ C. Phillip Shelor, ${ }^{\mathrm{c}}$ Drew Henderson, ${ }^{\mathrm{c}}$ Akinde Florence Kadjo, ${ }^{\mathrm{c}}$ Corey Roelke,,${ }^{\mathrm{b}, \mathrm{f}}$ Paul F. Hudak, ${ }^{\mathrm{g}}$ Taylour Burton, ${ }^{h}$ Hanadi S. Rifai, ${ }^{h}$ and Kevin A. Schug ${ }^{b, c},{ }^{*}$

\section{AUTHOR INFORMATION:}

a Inform Environmental, LLC, Dallas TX 75206

${ }^{\mathrm{b}}$ Affiliate of the Collaborative Laboratories for Environmental Analysis and Remediation, The University of Texas at Arlington, Arlington TX 76019

${ }^{\mathrm{C}}$ Department of Chemistry and Biochemistry, The University of Texas at Arlington, Arlington TX 76019

d Department of Biological Sciences, Tarleton State University, Stephenville TX 76401

e SWCA Environmental Consultants, Arlington TX 76006

${ }^{f}$ Department of Biology, The University of Texas at Arlington, Arlington TX 76019

${ }^{9}$ Department of Geography, University of North Texas, Denton, TX 76203

${ }^{\mathrm{h}}$ Department of Civil and Environmental Engineering, University of Houston, Houston, TX 77204

${ }^{\dagger}$ These authors contributed equally to this work

" Present address: Water Quality Protection Division, United States Environmental Protection Agency, Dallas TX 75202

Corresponding authors. Correspondence should be addressed to: Inform Environmental, LLC, 6060 N. Central Expressway, Suite 500, Dallas, TX 75206 (ph) 915-694-7132; (email) zac@informenv.com; and/or Department of Chemistry \& Biochemistry, The University of Texas at Arlington, 700 Planetarium PI., Box 19065, Arlington TX 76019; (ph) 817-272-3541; (email) kschug@uta.edu

KEYWORDS: Groundwater quality, unconventional drilling, volatile organic carbons

Author contributions: ZLH, DDC, BEF, JMM, CPS and KAS designed research; ZLH, DDC, JTT, and CER recruited volunteer study participants and collected samples; SK, CPS, DJH, AFK, CER, JBT, BEF, JMM, PH, and JLW conducted analytical chemistry analyses, hydrogeology descriptions, geospatial analyses, statistical analyses, and performed quality checks and verification of all data collected; BEF, JMM, ZLH, DDC, and JLW analyzed data and provided conclusions for statistical analyses and geospatial relationships; TB and HR analyzed UOG drilling localities and common industrial practices; AFK, CPS, PH, TB, HR, CER and JLW provided comments, conclusions, and corrections on earlier versions of the manuscript; ZLH, BEF, DDC, JMM, PH and KAS wrote the paper.

Disclaimer: This work is not a product of the United States Government or the United States Environmental Protection Agency, and the authors did not do this work in any governmental capacity. The views expressed are those of the authors only and do not necessarily represent those of the United States or the United States Environmental Protection Agency. 


\section{ABSTRACT}

7

8

69

1

The exploration of unconventional shale energy reserves and the extensive use of hydraulic fracturing during well stimulation have raised concerns about the potential effects of unconventional oil and gas extraction (UOG) on the environment. Most accounts of groundwater contamination have focused primarily on the compositional analysis of dissolved gases to address whether UOG activities have had deleterious effects on overlying aquifers. Here, we present an analysis of 550 groundwater samples collected from private and public supply water wells drawing from aquifers overlying the Barnett shale formation of Texas. We detected multiple volatile organic carbon compounds throughout the region, including various alcohols, the BTEX family of compounds, and several chlorinated compounds. These data do not necessarily identify UOG activities as the source of contamination; however, they do provide a strong impetus for further monitoring and analysis of groundwater quality in this region as many of the compounds we detected are known to be associated with UOG techniques.

0

2




\section{INTRODUCTION}

The potential effects of unconventional oil and gas (UOG) drilling activities on groundwater quality have led to much concern despite a relative lack of scientific data. Recently, investigations in the Marcellus and Barnett shale formations in Pennsylvania and

83 Texas found elevated levels of dissolved methane ${ }^{1,2}$ and heavy metals ${ }^{3}$ in private water wells located near unconventional drilling sites. A number of extraction processes are utilized during unconventional shale exploration including directional drilling, shale acidization, and hydraulic fracturing, in which large quantities of water, proppants, and chemical additives are used to extract sequestered hydrocarbons. Additives used during hydraulic fracturing include viscosifiers, descaling agents, anti-corrosive compounds, lubricants, pH stabilizers, and other solvents that could be harmful if introduced into the environment. ${ }^{4}$ Instances of chemical contamination can result from casing failures, which happen in approximately $3 \%$ of new gas well operations, ${ }^{4}$ although recent findings indicate failure rates closer to $12 \%$ within the first year of operation. ${ }^{5}$ Recent research has shown that hydraulic fracturing could potentially alter contaminant pathways to aquifers via increased advective transport and/or flow through existing fractures widened by UOG activities. ${ }^{6} 7$ Additionally, surface sources such as mishandled waste fluid and produced waters or spills of UOG fluids during stimulation or completion of wells may contaminate groundwater, and shallow water wells may be vulnerable to such contamination. ${ }^{8}$

One of the more active regions for UOG drilling is in north-central Texas where the Barnett shale formation supports approximately 20,000 UOG wells. This region includes a portion of the Dallas-Fort Worth metropolitan area and outlying areas, and groundwater is

101 potentially vulnerable to contamination from various urban and rural sources. The Trinity and 102 Woodbine aquifers overlying the Barnett shale formation have historically been described as 103 good quality with low levels of heavy metals such as arsenic, selenium, strontium, and barium 
104 and naturally elevated levels of total dissolved solids (TDS). ${ }^{9}$ However, recent research on

105 groundwater quality near Barnett shale UOG activities identified higher concentrations of 106 heavy metals compared to historical data for this region. ${ }^{3}$ For more detailed information 107 regarding historical water quality in aquifers overlying the Barnett shale formation, we refer

108 the reader to Fontenot et al. ${ }^{3}$ Here, we present an updated analysis of groundwater quality in 109 aquifers overlying the Barnett shale and adjacent areas of north-central Texas. The objectives 110 of this study are to assess whether or not UOG activity may have had an impact on 111 groundwater quality by screening for the presence of elevated natural constituents and

112 contaminants potentially related to UOG activity, examining correlations among groundwater 113 constituents, and to identify changes in groundwater quality since the previous study of

114 Fontenot et al. ${ }^{3}$ A total of 550 groundwater samples were screened for the presence of 115 chemical compounds used in hydraulic fracturing, as well as for various metals and other 116 dissolved ions. We detected elevated levels of 10 different metals and the presence of 19 117 different chemical compounds, including benzene, toluene, ethyl benzene and xylene (BTEX).

118 These results constitute the largest analysis of groundwater quality in aquifers overlying a 119 shale formation associated with UOG activities.

\section{MATERIALS AND METHODS}

\section{2.1. Hydrogeology.}

123 Groundwater samples $(n=550)$ were collected from water wells that draw from the

124 Trinity and Woodbine aquifers overlying the Barnett shale formation of Texas (Hereafter

125 referred to as the "Barnett shale region"; Figure 1). The Texas Water Development Board 126 classifies the Trinity and Woodbine aquifers as primary and secondary aquifers, respectively.

127 Regionally, groundwater in the study area flows southeastward, although numerous 128 groundwater production wells in the area create localized cones of depression in the water 129 table potentiometric surface. 
Cretaceous sand formations of the Trinity Group outcrop in a north-trending band and

131 dip underground to the east, where the aquifer becomes confined. The Trinity Group consists

132 of three formations, from bottom to top: Twin Mountains, Glen Rose, and Paluxy. The Twin

133 Mountains formation includes sand, shale, clay, and a basal gravel and conglomerate. ${ }^{10}$ Major

134 constituents of the Glen Rose formation, a confining unit, include limestone, marl, shale, and anhydrite. Mainly sand and shale make up the Paluxy Formation. The Glen Rose Formation is

136 absent north of central Wise County; here, the Paluxy and Twin Mountains Formations merge

137 together to form the Antlers Formation. Precipitation and seepage from reservoirs and

138 streams recharge the unconfined Trinity outcrop zone. ${ }^{11}$ Eastward, leakage through confining

139 beds recharges the aquifer. ${ }^{12}$ Annual recharge to the aquifer averages approximately 2.5 $\mathrm{cm}^{13}$

The Woodbine Aquifer consists of ferruginous sand and sandstone interbedded with

142 shale and clay of the Cretaceous Woodbine Formation. Discontinuous seams of lignite,

143 gypsum, and volcanic ash are also present in the Woodbine Formation. ${ }^{10}$ Overlying the Trinity

144 Group and intervening strata, the Woodbine Formation also outcrops in the study area and

145 dips eastward. Unconfined conditions occur in the outcrop zone, and artesian conditions

146 prevail downdip. ${ }^{11}$ Precipitation on the outcrop zone and seepage from lakes and streams

147 recharge the aquifer. Average annual recharge to the aquifer is approximately $2 \mathrm{~cm} .{ }^{13}$

\section{$148 \quad$ 2.2. Sample Collection.}

Private water well samples $(n=550)$ were collected from wells tapping the Trinity and Woodbine aquifers. Of the 550 samples, 350 came from private wells serving residential

151 purposes, while 59 samples came from agricultural water wells, and 141 samples came from

152 municipal or public water supply wells servicing communities throughout the Dallas-Fort

153 Worth Metroplex. Approximately $83 \%$ of the samples were collected from wells tapping 154 aquifers located above the Barnett shale formation, a feature populated by more than 20,000 155 UOG wells since the early 2000s. Samples were collected without prior knowledge of the ACS Paragon Plus Environment 
156 UOG activity in the area and all geospatial analyses were performed ex post facto. Samples

157 were collected throughout Montague, Wise, Parker, Hood, Tarrant, Somervell, Johnson, Hill,

158 Ellis, Dallas, Denton, Collin and Cooke counties (Figure 1). Water well depths ranged from

159 10-1200 m according to wellowners, and well depth tends to increase eastward in both

160 aquifers, following the slope of the principal water-bearing formations into the subsurface.

161 Sites were selected on the basis of well owner participation and our ability to collect

162 unfiltered/untreated water that would be representative of the underlying aquifers, as

163 described previously. ${ }^{3}$ Measurements for basic water quality parameters such as

164 temperature, dissolved oxygen (DO), conductivity, total dissolved solids (TDS), salinity, $\mathrm{pH}$

165 and oxidation-reduction potential (ORP) were performed with a YSI Professional Plus multi-

166 parametric probe, and each water well was purged until measurements for these parameters

167 had stabilized, indicating that samples were representative of fresh groundwater from the

168 underlying aquifer. Two duplicate samples from each private water well were collected in

169 photo-resistant HDPE bottles with no headspace. Samples for metals analysis were filtered

170 and preserved with nitric acid to a pH less than 2 and stored at $4{ }^{\circ} \mathrm{C}$ until laboratory

171 procedures could be performed. Samples for anion analysis were preserved with chloroform

172 and frozen to reduce microbial degradation. All laboratory measurements were made within

17314 days, except for the metal analysis, which was measured within 6 months of collection, per

174 suggested holding times from the Environmental Protection Agency (EPA). ${ }^{14}$ Method blanks

175 and random analytical replicates were performed for each set of samples collected across

176 multiple trips from December 2013 to August 2014 (See supporting information for exact

177 sampling dates).

$178 \quad$ 2.3. Analysis.

179 Chemical analyses included gas chromatography-mass spectrometry (GC-MS),

180 headspace-gas chromatography (HS-GC), inductively coupled plasma - mass spectrometry

181 and - optical emission spectroscopy (ICP-MS and ICP-OES), and ion chromatography (IC). 
182 Specific organics were selected from a 2011 Congressional Report on hydraulic fracturing

183 fluid ingredients ${ }^{15}$ as well as frequently listed components of UOG fluids in the national

184 hydraulic fracturing chemical registry (www.fracfocus.org). ${ }^{16}$ These include metal ions,

185 alcohols, aromatic compounds, aldehydes, amines, and others (See Supporting Information

186 for a full list of screened species). Whenever possible, we evaluated constituents in the

187 context of their respective Primary or Secondary Maximum Contaminant Limits (MCL), Health

188 Advisory Levels, or other suggested levels as provided in the United States Environmental

189 Protection Agency's (EPA) Drinking Water Standards. ${ }^{17}$

190 Information about UOG drilling activity in the region was obtained from

191 www.fracfocus.org ${ }^{16}$ and the Texas Railroad Commission, ${ }^{18}$ the governing body for oil and

192 gas drilling in the state of Texas. Geospatial analyses were conducted using ArcGIS 10.1. ${ }^{19}$

193 Because we obtained measurements of water quality variables for nearly all sample wells, we

194 evaluated the relationship between measures of water quality and both distance to nearest

195 UOG well and depth of sample well using multiple regression and model selection based on

196 adjusted $R^{2}$ values. We noted spurious positive relationships between distance to nearest

197 UOG well and some water quality variables, and thus we elected to not use this predictor

198 variable further (Table 1; see Results and Discussion below). We evaluated bivariate

199 relationships for particular variables for which we had a priori reason to assume they may be

200 related, and derived a composite variable for chloride, bromide, and nitrate using a principal

201 components analysis (PCA) of these three variables based on the correlation matrix. Before

202 all analyses, we log-transformed both distance measures and $\log _{10}$-transformed remaining

203 variables to normalize distributions. To evaluate geographic patterns at a coarse scale, we

204 used Pearson's chi-squared tests of independence for frequency of water well samples with

205 either detection or EPA's Drinking Water Maximum Contaminant Limit (MCL) exceedances of

206 selected compounds for each county with $\geq 40$ total samples. This analysis allowed us to

207 evaluate whether particular counties in north-central Texas exhibited higher or lower than

208 expected frequencies of samples with particular compounds. All regression, correlation, and

209 principal component analyses were performed in Systat $12.02^{20}$ and chi-squared tests were

210 performed in the software program $R^{21}$ 


\section{3. RESULTS AND DISCUSSION}

A total of 550 groundwater samples was collected from private and public water supply wells throughout the Barnett shale region. Sampled water wells ranged from $90 \mathrm{~m}$ away from the nearest UOG well in areas of active UOG extraction to 47,220 m away from the nearest UOG well in areas outside of the Barnett shale, with a median and mean distance of 807 and 2,315 $\mathrm{m}$ respectively. The large difference between median and mean values reflects the influence of extreme outliers at the higher end of this range. Of the 550 samples, $339(61.6 \%)$ were collected from water wells within $1 \mathrm{~km}$ of the nearest UOG well, which likely reflects the increased willingness of well owners to participate in this research in more heavily drilled areas. Unfortunately, this opportunistic and necessarily biased sampling hindered our ability to make meaningful inferences regarding levels of contamination as a function of distance from nearest UOG well for several reasons: (1) the expectation of no detection of a given contaminant for a given sample well assumes uniform and substantial sampling across a gradient of distances from UOG wells, but the distribution of well samples as a function of distance from UOG well was strongly right-skewed; (2) the radius of $1 \mathrm{~km}$ for the majority of our groundwater samples is not an adequate distance to detect meaningful statistical patterns of contaminant diffusion from the site of UOG wells; and (3) distance to nearest UOG well is positively correlated with depth of groundwater well $(r=0.36, p<0.0001)$ (SI Figure 1), a 230 potential confounding variable (see water quality results below). Water wells in the eastern 231 part of the study area tend to be both farther away from UOG wells (because the Barnett 232 shale formation is westward) and deeper (because the aquifers deepen eastward); thus, 233 explaining observation (3) above. We observed some weak, positive correlations between 234 UOG wells and some analytes, but interpret these results as spurious for the reasons 235 mentioned above in conjunction with the following additional considerations: (1) positive 236 relationships between analyte concentrations and distance from UOG well have no 237 reasonable causal basis, but are readily explained by the correlation with depth of sample ACS Paragon Plus Environment 
238 well, (2) explanatory power of the correlations using distance from UOG well was consistently

239 lower than for correlations with depth of well, suggesting that between these collinear factors, 240 it is more parsimonious to assume that relationships with distance from UOG well are 241 confounded.

\section{$242 \quad$ 3.1. Water Quality}

Multiple regression analyses of basic water quality parameters as a function of 244 distance from nearest UOG well (distance) and depth of groundwater well sample (depth) 245 revealed that depth is a substantially better predictor of overall water quality than is distance, 246 albeit most relationships were weak (Table 1). In general, TDS concentrations tend to 247 increase eastward in the study area, as groundwater moves along the principal water-bearing 248 formations of the Trinity and Woodbine aquifers. With travel, increased residence (contact) 249 time facilitates more dissolution of aquifer constituents. For example, sodium, chloride, 250 sulfate, and various other constituents tend to increase eastward, as does water well depth. 251 All variables showed a positive relationship with depth except for dissolved oxygen, which showed a negative relationship with depth. Dissolved oxygen levels tend to be higher in shallower, unconfined areas of the aquifer where groundwater mixes with gases in the vadose zone. Values for $\mathrm{pH}$ exhibited a nonlinear relationship with depth, with low values in shallow wells, high values at intermediate depths, and a slight trend toward neutral $\mathrm{pH}$ for the deepest wells. Values for $\mathrm{pH}$ also tend to be lower in the unconfined outcrop zones, where slightly acidic rainwater recharges the aquifers. Model selection indicated that for many variables, an additive or interaction model best explained the total variance in the dataset; however, the low $R^{2}$ adj values for models including only UOG distance for each of these response variables, and the collinearity between depth and UOG distance, suggest that the inclusion of distance 261 in these models is spurious. Basic water quality analyses revealed the consistent occurrence 262 of elevated TDS throughout the 13 counties sampled. Of the 550 samples, 344 exceeded the 263 Secondary MCL of $500 \mathrm{mg} / \mathrm{L}$ suggested by the EPA. TDS values ranged from 68.5 to 3328 
$264 \mathrm{mg} / \mathrm{L}$ with an average slightly above the MCL (630.3 mg/L). Measurements also showed $\mathrm{pH}$ 265 values ranging from 5.3 to 9.4 with a mean value of 8.1 . Collectively, 254 samples were 266 outside of the range of 6.5-8.5 suggested by the EPA MCL, with 15 samples having $\mathrm{pH}$ 267 measurements below 6.5 and 239 samples having $\mathrm{pH}$ measurements above 8.5. Elevated 268 TDS and $\mathrm{pH}$ measurements are not unusual for the Trinity and Woodbine aquifers, as similar 269 results have been reported previously. 32

\subsection{Anions in Groundwater}

Subsequent analyses using ion chromatography (IC) were performed to assess the prevalence of selected water quality anions in the Trinity and Woodbine aquifers. Nitrate and fluoride were measured to characterize the relative effect of agricultural surface activities on the underlying groundwater. Nitrate was detected in 223 of the 550 samples, and 2 samples were found to be elevated above the $44.3 \mathrm{mg} / \mathrm{L} \mathrm{MCL}$, with a maximum value of $55.7 \mathrm{mg} / \mathrm{L}$. As a whole, nitrate values were higher (median $=0.95 \mathrm{mg} / \mathrm{L}$ ) than those previously reported in the Trinity and Woodbine aquifers, each with median values of $0.4 \mathrm{mg} / \mathrm{L} .^{22}$ High levels of nitrate in shallow groundwater often stem from agricultural processes, such as the use of fertilizer and organic manures, as well as septic systems and decaying vegetation. Nitrate values tend to be higher in the outcrop zones of the aquifers, where they are more vulnerable to contaminants originating from the land surface. Generally, the outcrop zone of the Trinity aquifer is more rural than that of the Woodbine aquifer, and agricultural activity in the Trinity outcrop zone may account for higher median nitrate values observed in that aquifer. Fluoride was found to be elevated above its $4 \mathrm{mg} / \mathrm{L} \mathrm{MCL}$ in 2 wells with a median value of $0.3 \mathrm{mg} / \mathrm{L}$, less than previous measurements collected in the $2000 \mathrm{~s}(0.7$ and $1.3 \mathrm{mg} / \mathrm{L}$ for the Trinity and the Woodbine aquifers, respectively). ${ }^{22}$ Elevated fluoride levels may originate from phosphate 287 fertilizers and mineral constituents in the aquifers, especially in the Woodbine aquifer. ${ }^{23,}{ }^{24}$ For 288 example, fluoride is known to occur at relatively high levels in parts of the Woodbine aquifer, ${ }^{24}$ 289 a plausible source being volcanic ash deposits. 
An overall prevalence of nitrate and the lack of covariation between nitrate and fluoride

$291(r=-0.05)$ suggest that they may be coming from different sources, such as agricultural 292 sources for nitrate and natural sources for fluoride. Sulfate levels (median value of $52.8 \mathrm{mg} / \mathrm{L}$ ) 293 were below those discovered in previous measurements; 79 and $114 \mathrm{mg} / \mathrm{L}$ for the Trinity and 294 Woodbine aquifers in samples collected in the $2000 \mathrm{~s} .{ }^{22}$ Chloride levels were also found to be 295 consistent with historical measurements with a median value of $25.4 \mathrm{mg} / \mathrm{L}$ compared to 35 and $36.3 \mathrm{mg} / \mathrm{L}$ discovered in samples previously collected from the Trinity and Woodbine 297 aquifers, respectively. ${ }^{22}$ However, chloride was found to be elevated above the $250 \mathrm{mg} / \mathrm{L} \mathrm{MCL}$ 298 threshold in 21 wells with a maximum value of $3373.8 \mathrm{mg} / \mathrm{L}$, a value over 3 times greater than 299 previously observed. ${ }^{22}$

Formation water in general contains elevated concentrations of chloride, bromide, sodium, and sulfate. ${ }^{25}$ Of these ions, bromide has recently been used when attempting to 302 identify formation water intrusion with the aquifer because of its naturally low abundance and conservative behavior in groundwater. High levels of chloride and bromide can be an indication of anthropogenic contamination, one possibility being UOG activity, ${ }^{26}$ a result of 305 groundwater mixing with produced water from the shale formation. ${ }^{25}$ Bromide was detected in 170 water wells ranging from 0.03 to $6.4 \mathrm{mg} / \mathrm{L}$ (Supporting Information Descriptive Statistics 307 Table). Previous groundwater monitoring efforts within a few of the counties sampled in this 308 study showed bromide concentrations up to approximately $3.5 \mathrm{mg} / \mathrm{L}$, with an outlier of 8.4 $\mathrm{mg} / \mathrm{L}$; however, bromide was not detected in the majority of samples. ${ }^{26,27}$

Overall, bromide showed a moderately high positive correlation with chloride when 311 both compounds occurred together $(r=0.32, p<0.0001)$, with a particularly strong log-linear 312 trend along a ratio within the $\sim 100-150$ range (Figure 2). Additionally, a composite variable 313 derived from a PCA of chloride, bromide, and nitrate (all three compounds were strongly 314 positively correlated with the first principal component axis, which had an eigenvalue of 1.351 315 and explained $45.1 \%$ of the total variance in this combination of variables) was negatively ACS Paragon Plus Environment 
correlated with depth of groundwater well $(r=-0.34, p=0.002)$, suggesting a surface source

317 may contribute to observed concentrations of these contaminants (SI Figure 2). It should be 318 noted that denitrification and reducing conditions at higher depths could also lead to this 319 correlation.

Calculating the chloride/bromide mass ratio of groundwater samples can be useful for sourcing contamination or mixing of sources. ${ }^{28}$ Previous investigators used chloride/bromide ratios to identify potential sources of groundwater contamination. ${ }^{29}$ Based upon several published studies, chloride/bromide ratios generally range from 50-150 in atmospheric precipitation, 300-600 in domestic sewage, 1000-10,000 in dissolved evaporites, and 100-200 in unimpaired, shallow groundwater. ${ }^{30}$ In oilfield brine (formation water), chloride/bromide ratios vary widely, but typically fall between 100 and 300 . This ratio can also be achieved by mixing unimpaired groundwater with groundwater impaired by evaporites. Mixing of groundwater from multiple sources leads to intermediate ratios of these conservative ions. Of the 550 samples, $170(30.9 \%)$ had detectable amounts of bromide. The median chloride/bromide ratio of all samples with detectable bromide was 239 , with a minimum of 3 and a maximum of 1465 . Of the 170 wells with bromide, 97 wells (57.1\%) had a chloride/bromide ratio between 100 and 300 . Of the 550 well samples, $17.6 \%$ had a chloride/bromide ratio between 100 and 300. A localized area in southern Parker County showed the highest chloride/bromide ratios, ranging from 725 to 1465 . These relatively high ratios may reflect dissolution of evaporites present in the aquifers or confining formations. A less likely, though plausible explanation is saline surface water (e.g. waters impacted by road salt ${ }^{31}$ ) mixing with relatively shallow groundwater in or near the Trinity aquifer's outcrop zone. Only eight samples had a chloride/bromide ratio less than 10. In previous studies, such extremely low ratios have been attributed to mixing of groundwater with runoff impacted by 340 brominated gasoline additives. ${ }^{32,33}$ Five of the eight samples with chloride/bromide ratios 341 below 10 are located adjacent to a state highway or interstate. 


\section{3.3. Metals Analysis}

ICP-MS and ICP-OES analyses were used to evaluate the concentrations of 15

different metal ions that are good indicators of groundwater condition. Of the 550 collected samples, 10 were found to have arsenic levels above the $10 \mu \mathrm{g} / \mathrm{L} \mathrm{MCL}$ threshold, with a maximum value of $114 \mu \mathrm{g} / \mathrm{L}$. Similarly, strontium was found to be elevated above the $4.0 \mathrm{mg} / \mathrm{L}$ MCL threshold in 9 wells with a maximum detection of $8.9 \mathrm{mg} / \mathrm{L}$. Selenium was detected more frequently than in previous investigations ${ }^{3}$ (detected in 507 of the 550 samples), but in much lower concentrations than the MCL. A prior analysis of 100 private wells in the Barnett shale by Fontenot et al. revealed higher levels of arsenic, barium, selenium, and strontium than seen in this study. ${ }^{3}$ Fontenot et al. suggested that these naturally occurring groundwater constituents could concentrate in iron-oxide rust/scale formations that can build up in water wells, which could then be liberated by mechanical perturbances of private water wells such as those generated by nearby UOG activities. ${ }^{3}$ While this remains a plausible explanation for the elevated concentrations of heavy metals observed by Fontenot et al., ${ }^{3}$ decreased drilling activity and a likely decrease in mechanical disturbances in 2014 compared to 2011 (1,902 permits issued in 2013-14 versus 4,136 in 2010-2011), may explain the decreased levels of dissolved metals compared to previous measurements. ${ }^{34}$

These ions can also originate from natural sources such as the mineral constituents of

360 the aquifers. Changes in oxygen-reduction potential can also change valence states, which 361 may liberate or bind some of these species. As such, some fluctuation is expected to occur 362 naturally, as well as be induced by changes in water levels and redox conditions caused by 363 pumping. Compared to the previous measurements collected by Fontenot et al. ${ }^{3}$, ORP values 364 suggested a more oxidative environment with a median value of $80.7 \mathrm{mV}$ compared to a 365 previous median value of 28.6. Coupled with an increase in $\mathrm{pH}$ from 7.69 to 8.30 , the current 366 conditions are less favorable for dissolved metals compared to the conditions observed in 367 2011. Additionally, the samples in Fontenot et al. ${ }^{3}$ were not acidified and filtered as they were ACS Paragon Plus Environment 
sampling for total metals not dissolved metals as in the current study. However, it should be

noted that this difference in sampling protocol likely cannot account for the large variations in metals concentrations between the two studies as total metals analysis usually leads to a more conservative concentration estimate than dissolved metals analysis.

Beryllium, iron, and molybdenum were also elevated in 75,87 , and 187 of the 373 groundwater samples, respectively, with a higher than expected frequency of MCL 374 exceedances in Montague County based on chi-squared tests (Table 2). Beryllium exceedances $(0.004 \mathrm{mg} / \mathrm{L} \mathrm{MCL})$ were also detected at a higher than expected frequency in Parker and Tarrant counties; whereas iron exceedances ( $0.3 \mathrm{mg} / \mathrm{L} \mathrm{MCL})$ levels were also higher than expected in Cooke and Johnson counties, and molybdenum exceedances (0.04 $\mathrm{mg} / \mathrm{L} \mathrm{MCL}$ ) were more frequent in Parker and Wise counties (Table 2). The significance of these three ions remains to be determined, as there is no historical precedent for reference.

Other metal ions found in excess of their respective MCL values include barium (1 sample), chromium (1 sample), copper (1 sample), nickel (16 samples), and zinc (1 sample).

\subsection{Gas Chromatography Analyses}

GC-MS and HS-GC analyses revealed the most striking results of this study. Of the 39

volatile and semi-volatile compounds that were screened, 13 compounds were detected at least once. In particular, methanol and/or ethanol were detected in 35 and 240 wells respectively with average concentrations of 0.5 and $3.2 \mathrm{mg} / \mathrm{L}$ and maximum concentrations of 44.6 and $394.2 \mathrm{mg} / \mathrm{L}$, respectively. Methanol and ethanol both are used extensively in unconventional drilling as anti-corrosive agents and gelling agents (www.fracfocus.org); ${ }^{16}$ however, these two alcohols can also be produced in situ. Methanol can be produced through 390 the digestion of methane by methanotrophic bacteria, ${ }^{35}$ whereas ethanol can be produced 391 organically by thermophilic bacteria, ${ }^{36}$ albeit typically in much smaller concentrations than was 392 observed here. Both methanol and ethanol were found in 19 wells from Denton, Parker, and 393 Montague counties, in localized areas similar to the areas exhibiting high bromide. These two ACS Paragon Plus Environment 
394 alcohols have been detected previously in this region, but at that time, no conclusions could 395 be made about their origin. ${ }^{3}$ Propargyl alcohol and isopropyl alcohol were also detected in 396155 and 8 water wells, respectively, with maximum concentrations of 26.4 and $9.4 \mathrm{mg} / \mathrm{L}$, 397 respectively. Moreover, when present together, ethanol levels were correlated with propargyl 398 alcohol levels $(r=0.53, p<0.0001)$, but not with methanol levels $(r=-0.13, p=0.517)$. The 399 source of these alcohols remains to be determined; however, methanol, ethanol, and 400 propargyl alcohol were all detected at a greater percentage within the Barnett shale $(89,92$, 401 and $90 \%$, respectively) than the percentage of total samples collected within the producing 402 403 region (83.1\%). In particular, ethanol was detected at a higher frequency than expected in Montague, Parker, Tarrant, and Wise counties based on chi-squared analysis; whereas propargyl alcohol was found at a higher incidence in samples from Johnson, Parker, Tarrant and Wise counties (Table 2). These counties comprise the most productive sub-region of the Barnett shale; 18,559 UOG well stimulation events were recorded here since the year 2000, and collectively, these species constitute a specific sub-set of compounds commonly used in unconventional well stimulation per the 2011 Congressional Report on hydraulic fracturing. ${ }^{15}$ Of the four alcohol species that were detected throughout the study, only methanol showed a negative correlation with well depth $(r=-0.39, p=0.034)$, suggesting the source of the methanol originated from the surface, as could result from the mishandling of waste solutions and/or fluid spills. The correlations between well depth and ethanol and propargyl alcohol were not significant $(p>0.05)$, and there were insufficient detections of isopropyl alcohol to perform a correlative analysis with well depth.

Dichloromethane (DCM) was detected in 122 samples, with 121 of these detections exceeding the suggested $\mathrm{MCL}$ of $0.005 \mathrm{mg} / \mathrm{L}$, and $93 \%$ of the detections coming from samples collected within the Barnett shale region. DCM had a mean concentration of 0.08 $\mathrm{mg} / \mathrm{L}$ across the dataset, with a maximum concentration of $2.9 \mathrm{mg} / \mathrm{L}$. The source of this industrial solvent remains to be determined; however, DCM has been detected in a previous 
420 study of groundwater quality in the Permian Basin, a region in western Texas that has recently

421 seen increased UOG activity (Hildenbrand et al., in review). DCM has also been implicated in 422 air quality contamination events associated with unconventional drilling in Colorado ${ }^{37}$ and 423 UOG flowback water. ${ }^{38}$ There is no known natural occurrence of DCM except through the 424 microbial degradation of chlorinated solvents with higher degrees of chlorination like 425 chloroform. ${ }^{39}$ This explanation is plausible and could apply to the data set given that 426 chloroform was also detected in 330 of the collected samples, and in 41 of the 122 samples 427 where DCM was detected. Consistent with this explanation, a scatterplot of DCM levels as a 428 function of chloroform levels (when both compounds were present in a sample) revealed two 429 discrete clusters of samples with distinct, inverse ratios of these compounds (Figure 3). For 430 one cluster of samples, the ratio of $\mathrm{DCM} /$ chloroform was $\sim 62: 1$, whereas in the other, the 431 dominant compound was chloroform with a DCM/chloroform ratio of $\sim 1: 32$. These striking 432 clusters may be the signatures of two widespread and temporally distinct types of 433 contamination events. The cluster with the higher DCM/chloroform ratio may represent an 434 older contamination event, in which microbial degradation of chloroform had progressed 435 farther than in the more recent event, which accordingly exhibits less degradation of 436 chloroform to DCM. Regardless, the consistent, but distinct, ratios of these compounds for 437 samples constituting those clusters is striking. Alternatively, DCM may also have been 438 introduced from an exogenous source. DCM is a commonly used degreasing agent, ${ }^{40}$ and 439 raw use of large volumes of concentrated DCM at the well pad could present a possible 440 pathway for contaminating nearby surface water and shallow groundwater. A breach of 441 flowback waste pits, whether from overflow or faulty linings, can also introduce DCM and 442 many other species into the surface environment. ${ }^{41} \mathrm{~A}$ spill of the solvent solution would 443 account for DCM being present without other chlorinated species. Additionally, 444 trichloroethylene (TCE) was detected in 14 samples at very low levels ranging from 0 to 0.04 $445 \mathrm{mg} / \mathrm{L}$, and was detected exclusively from samples collected within the Barnett shale region. 
446 Collectively, a possible co-migration of dichloromethane, chloroform, and trichloroethylene is 447 consistent with the previous detection of these chlorinated compounds in flowback water from 448 unconventional drilling operations. ${ }^{42}$

At least one of the BTEX (benzene, toluene, ethylbenzene and xylene) class of 450 compounds was detected in 381 of 550 collected samples, and 10 wells had detectable 451 amounts of all four BTEX compounds. These compounds collectively can be found in 452 hydrocarbon fuels, whether raw, processed, or waste, and some individually as industrial 453 solvents or as intermediates in the chemical industry. Benzene was detected in 34 wells, $91 \%$ 454 of which were detected from samples collected within the Barnett shale region. Benzene 455 concentrations exceeded the MCL guideline of $0.005 \mathrm{mg} / \mathrm{L}$ in all 34 of the detections and 456 but salt contamination has been identified in association with injection wells and plugged oil reached a maximum concentration of $0.09 \mathrm{mg} / \mathrm{L}$. Toluene, ethylbenzene, and three xylene isomers were also found to be prevalent throughout the Trinity and Woodbine aquifers, being detected in 240, 22, and 240 wells respectively, although at trace concentrations well below their individual MCL values. Interestingly, $83 \%$ of samples within Montague County (55 of 66 ) contained a BTEX compound. This area houses underground injection wells for drilling waste disposal across north-central Texas and Oklahoma, thus it is exposed to the largest volume of produced waters in the region through either trucked or injected water, which must be disposed of with great care. ${ }^{41}$ Furthermore, this area is also vulnerable to contamination because it occupies the unconfined outcrop zone of the Trinity aquifer. Of the four BTEX compounds, toluene was the only constituent to have a significant relationship with respect to well depth $(r=-0.20, p=0.003)$. This observation is consistent with that of methanol and well depth, suggesting that the source of these two constituents originated from the surface.

No research has been reported on organics leaching from underground injection wells, and gas wells in southeast Texas. ${ }^{43}$ Compared to equivalent studies, the abundance of BTEX compounds in the Barnett shale region is consistent with the characterization of produced ACS Paragon Plus Environment 
472 water. Previous findings have detected various BTEX compounds in fracturing influents 473 (mixed fluids before injection) across 22 drilling sites of the Marcellus and Barnett shales. The 474 concentration and occurrence of these BTEX compounds increased in samples collected after 475 multiple days of flowback because of the influent's extended contact with the shale 476 formation. ${ }^{42}$ Cyclohexane was also detected in 221 of the 550 collected samples with a 477 maximum concentration of $1.3 \mathrm{mg} / \mathrm{L}$. Interestingly, $75 \%$ of the cyclohexane detections were 478 observed in samples collected within the Barnett shale, below the percentage of water 479 samples collected within the shale region (83\%). However, based on chi-squared analysis 480 cyclohexane was detected at higher than expected frequencies in Cooke, Denton, Johnson 481 and Hood counties, all of which are highly productive areas with respect to UOG extraction, 482 with the exception of Cooke County (645 UOG stimulation events since the year 2000; Table 483 2).

Collectively, these data constitute one of the largest studies of groundwater quality in a shale formation associated with UOG activities. The detection of numerous volatile organic compounds in aquifers above the Barnett shale does not necessarily implicate unconventional UOG extraction as the source of contamination; however, it does provide an impetus for 488 further monitoring and analysis of groundwater quality in this region.

\section{ASSOCIATED CONTENT}

\section{Supporting Information}

491 Additional materials and methods, figures, tables, and the complete water quality data set 492 referenced in the text. This information is available free of charge via the Internet at 493 http://pubs.acs.org.

\section{AUTHOR INFORMATION}

495 Corresponding Authors

496 *Phone: 817-272-3541. E-mail: kschug@uta.edu

497 *Phone: 915-694-7132. E-mail: zac@informenv.com 
499 "I Present address: Water Quality Protection Division, United States Environmental Protection

500 Agency, Dallas TX 75202

\section{Author Contributions}

$502{ }^{\dagger}$ These authors contributed equally to this work. Author contributions: ZLH, DDC, BEF, JMM, 503 CPS and KAS designed research; ZLH, DDC, JTT, and CER recruited volunteer study 504 participants and collected samples; SK, CPS, DJH, AFK, CER, JBT, BEF, JMM, PH, and JLW 505 506 507 conducted analytical chemistry analyses, hydrogeology descriptions, geospatial analyses, statistical analyses, and performed quality checks and verification of all data collected; BEF, JMM, ZLH, DDC, and JLW analyzed data and provided conclusions for statistical analyses and geospatial relationships; TB and HR analyzed UOG drilling localities and common industrial practices; AFK, CPS, PH, TB, HR, CER and JLW provided comments, conclusions, and corrections on earlier versions of the manuscript; ZLH, BEF, DDC, JMM, PH and KAS wrote the paper.

\section{Notes}

Disclaimer. This work is not a product of the United States Government or the United States Environmental Protection Agency, and the authors did not do this work in any governmental capacity. The views expressed are those of the authors only and do not necessarily represent those of the United States or the United States Environmental Protection Agency.

The authors declare no competing financial interest.

\section{ACKNOWLEDGMENTS}

We would like to thank the Shimadzu Institute for Research Technologies at The University of Texas at Arlington for research funds and instrumentation used in this study. We would like to thank Geotech Environmental Equipment of Carrolton, Texas, for their helpful guidance with basic water quality measurements. We would also like to thank all of the participating well owners for their contribution to this research, and to Drs. J.P. Nicot and Purnendu Dasgupta for all of their support and comments on earlier versions of this manuscript.

\section{REFERENCES}

1. Jackson, R. B.; Vengosh, A.; Darrah, T. H.; Warner, N. R.; Down, A.; Poreda, R. J.; Osborn, S. G.; Zhao, K.; Karr, J. D., Increased stray gas abundance in a subset of drinking water wells near Marcellus shale gas extraction. Proceedings of the National Academy of Sciences of the United States of America 2013, 110, (28), 11250-5.

2. Osborn, S. G.; Vengosh, A.; Warner, N. R.; Jackson, R. B., Methane contamination of drinking water accompanying gas-well drilling and hydraulic fracturing. Proceedings of the National Academy of Sciences of the United States of America 2011, 108, (20), 8172-6.

3. Fontenot, B. E.; Hunt, L. R.; Hildenbrand, Z. L.; Carlton, D. D., Jr.; Oka, H.; Walton, J. L.; Hopkins, D.; Osorio, A.; Bjorndal, B.; Hu, Q. H.; Schug, K. A., An evaluation of water quality in private drinking water wells near natural gas extraction sites in the barnett shale formation. Environmental science \& technology 2013, 47, (17), 10032-40.

4. $\quad$ Vidic, R. D.; Brantley, S. L.; Vandenbossche, J. M.; Yoxtheimer, D.; Abad, J. D., Impact of shale gas development on regional water quality. Science 2013, 340, (6134), 1235009.

5. Ingraffea, A. R.; Wells, M. T.; Santoro, R. L.; Shonkoff, S. B., Assessment and risk analysis of casing and cement impairment in oil and gas wells in Pennsylvania, 2000-2012. 
544 Proceedings of the National Academy of Sciences of the United States of America 2014, 111, 545 (30), 10955-60.

546 6. Saiers, J. E.; Barth, E., Potential contaminant pathways from hydraulically fractured 547 shale aquifers. Ground water 2012, 50, (6), 826-8; discussion 828-30.

7. Darrah, T. H.; Vengosh, A.; Jackson, R. B.; Warner, N. R.; Poreda, R. J., Noble gases identify the mechanisms of fugitive gas contamination in drinking-water wells overlying the Marcellus and Barnett Shales. Proceedings of the National Academy of Sciences of the United States of America 2014, 111, (39), 14076-81.

8. Assessment of the Potential Impacts of Hydraulic Fracturing for Oil and Gas on Drinking Water Resources; Environmental Protection Agency: Washington, DC, May 2015.

9. Reedy, R. C.; Scanlon, B.R.; Walden, S.; Strassberg. G. Naturally occurring groundwater contamination in Texas; Texas Water Development Board: 2011.

10. Peckman, R. C.; Sounders, V.I.; Dillard, J.W.; Baker, B. Reconnaissance investigation of the ground-water resources of the Trinity River Basin, Texas; Texas Water Commission: Austin, Texas, 1963.

11. Ground-water quality of Texas: an overview of natural and man-affected conditions; Texas Water Commission: 1989.

12. Rapp, K. B., Groundwater recharge in the Trinity aquifer, Central Texas. Baylor Geological Studies Bulletin 1988, 46, 1-34.

13. Baker, B.; Duffin, G.; Flores, R.; Lynch, T., Evaluation of water resources in part of central Texas. Texas Water Development Board: Austin, Texas, 1990.

14. Sampling Guidance for Unknown Contaminants in Drinking Water; Environmental Protection Agency: Washington, DC, 2008.

15. Chemicals Used in Hydraulic Fracturing; United States House of Representative Committee on Energy and Commerce: Washington, DC, 2011.

16. FracFocus. Chemical Disclosure Registry. http://fracfocus.org (July 9, 2014).

17. 2012 Edition of the Drinking Water Standards and Health Advisories; Environmental Protection Agency: Washington, DC, 2012.

18. Railroad Commission of Texas. http://www.rrc.state.tx.us (April 12, 2014).

19. ArcGIS Desktop 10.1, Environmental Systems Research Institute: Redlands, CA.

20. Systat, Version 12.02, Cranes Software International: San Jose, CA.

21. Team, R. C. R: A Language and Environment for Statistical Computing, R Foundation for Statistical Computing: 2014.

22. Chaudhuri, S.; Ale, S., Characterization of groundwater resources in the Trinity and Woodbine aquifers in Texas. The Science of the total environment 2013, 452-453, 333-48.

23. Brindha, K.; Rajesh, R.; Murugan, R.; Elango, L., Fluoride contamination in groundwater in parts of Nalgonda District, Andhra Pradesh, India. Environmental monitoring and assessment 2011, 172, (1-4), 481-92.

24. Nolan, B. T.; Hitt, K. J.; Ruddy, B. C., Probability of nitrate contamination of recently recharged groundwaters in the conterminous United States. Environmental science \& technology 2002, 36, (10), 2138-45.

25. Warner, N. R.; Christie, C. A.; Jackson, R. B.; Vengosh, A., Impacts of Shale Gas Wastewater Disposal on Water Quality in Western Pennsylvania. Environmental science \& technology 2013, 47, (20), pp 11849-11857/

26. Hudak, P. F., Solutes and Potential Sources in a Portion of the Trinity aquifer, Texas, USA. Carbonates and Evaporites 2010, 25, (1), 15-20.

27. Hudak, P. F., Lane use and groundwater quality in the Trinity Group outcrop of NorthCentral Texas, USA. Environment International 1997, 23, (4), 507-517.

28. Katz, B. G.; Eberts, S.M.; Kauffman, L.J., Using $\mathrm{Cl} / \mathrm{Br}$ ratios and other indicators to assess potential impacts on graoundwater quality from septics systems: a review and examples from principal aquifers in the United States. Journal of Hydrology 2011, 397, (3), 
595

596

597

598

599

600

601

602

603

604

605

606

607

608

609

610

611

612

613

614

615

616

617

618

619

620

621

622

623

624

625

626

627

628

629

630

631

632

633

634

635

636

637

638

151-166.

29. Whittemore, D. O., Geochemical differentiation of oil and gas brine from other saltwater sources contamination water resources: Case studies in Kansas and Oklahoma. Environmental Geosciences 1995, 2, (1), 15-31.

30. Davis, S. N.; Whittemore, D.O.; Fabryka-Martin, J., Uses of chloride/bromide ratios in studies of potable water. Ground water 1998, 36, (2), 338-350.

31. Richter, B. C.; Kreitler, C.W., Geochemical Techniques for Identifying Sources of Ground-Water Salinization. 1 ed.; CRC Press: 1993.

32. Flury, M.; Papritz, A., Bromide in the natural environment: occurrence and toxicity. Journal of Environmental Quality 1993, 22, (4), 747-758.

33. Vengosh, A.; Pankratov, I., Chloride/bromide and chloride/fluoride rations of domestic sewage effluents and associated contaminated ground water. Ground water 1998, 36, (5), 815-824.

34. Railroad Commssion of Texas. Barnett Shale drilling permits issued. http://www.rrc.state.tx.us/media/14482/barnettshaledrillingpermitsissued.pdf $\quad$ (March 12, 2014),

35. Corder, R. E.; Johnson, E.R., Vega, J.L., Clausen, E.C., Gaddy, J.L. Biological Production of Methanol from Methane; 1986.

36. Taylor, M. P.; Eley, K. L.; Martin, S.; Tuffin, M. I.; Burton, S. G.; Cowan, D. A., Thermophilic ethanologenesis: future prospects for second-generation bioethanol production. Trends in biotechnology 2009, 27, (7), 398-405.

37. Colborn, T. S., K.; Herrick, L.; Kwiatkowski, An Exploratory Study of Air Quality Near Natural Gas Operations. Human and Ecological Risk Assessment 2014, 20, (1), 86-105.

38. Maguire-Boyle, S. J.; Barron, A. R., Organic compounds in produced waters from shale gas wells. Environmental science. Processes \& impacts 2014, 16, (10), 2237-48.

39. Cappelletti, M.; Frascari, D.; Zannoni, D.; Fedi, S., Microbial degradation of chloroform. Applied microbiology and biotechnology 2012, 96, (6), 1395-409.

40. Dichloromethane in Drinking-water. In Guidelines for drinking-water quality, 2 ed.; World Health Organization: Geneva, 1996; Vol. 2.

41. Vengosh, A.; Jackson, R. B.; Warner, N.; Darrah, T. H.; Kondash, A., A critical review of the risks to water resources from unconventional shale gas development and hydraulic fracturing in the United States. Environmental science \& technology 2014, 48, (15), 8334-48.

42. Hayes, T. D.; Severin, B.F., Characterization of Flowback Waters from the Marcellus and Barnett; Gas Technology Institute: Des Plaines, IL, 2012.

43. Hudak, P. F.; Wachal, D. J., Effects of brine injection wells, dry holes, and plugged oil/gas wells on chloride, bromide, and barium concentrations in the Gulf Coast Aquifer, southeast Texas, USA. Environ Int 2001, 26, (7-8), 497-503. 


\section{FIGURES AND TABLES}

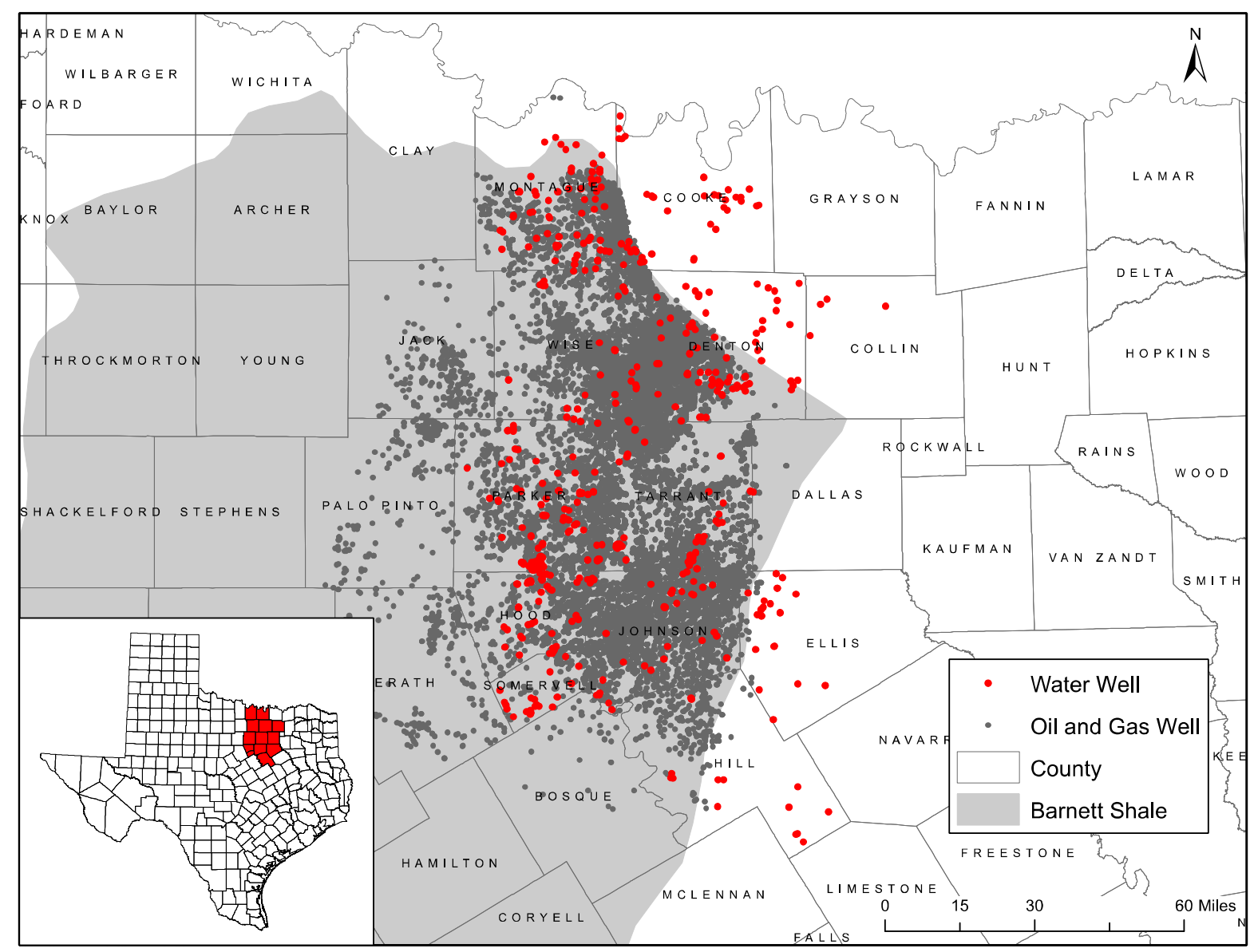

640

641 Figure 1. Sampled water wells (red) in relation to UOG wells (dark grey) throughout the 642 Barnett shale region (grey).

643 


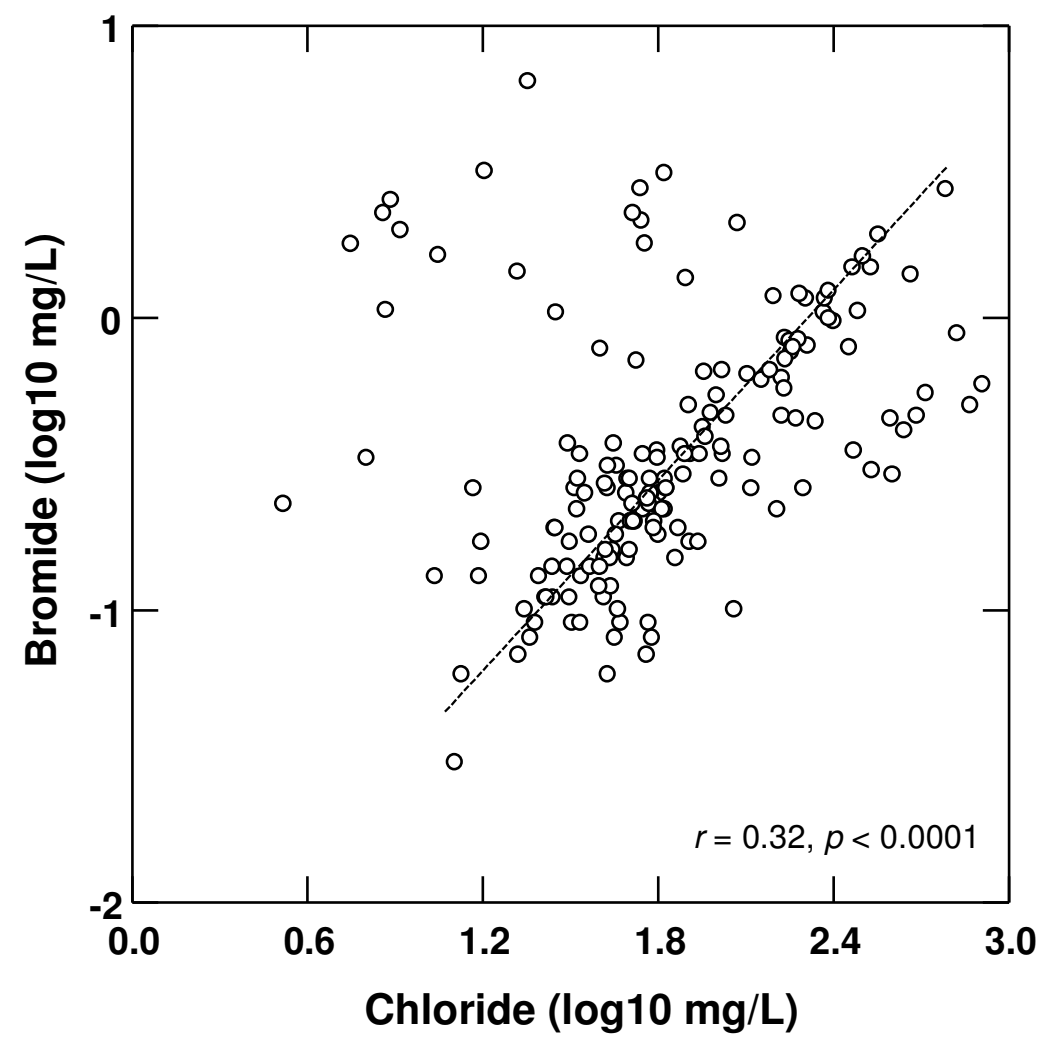

644

645 Figure 2. Bromide concentrations relative to chloride concentrations for samples with 646 detectable levels of bromide $(n=170)$. The dashed line is for visual purposes only, and 647 indicates a log-linear trend apparent in a subset of samples.

648

649

650 


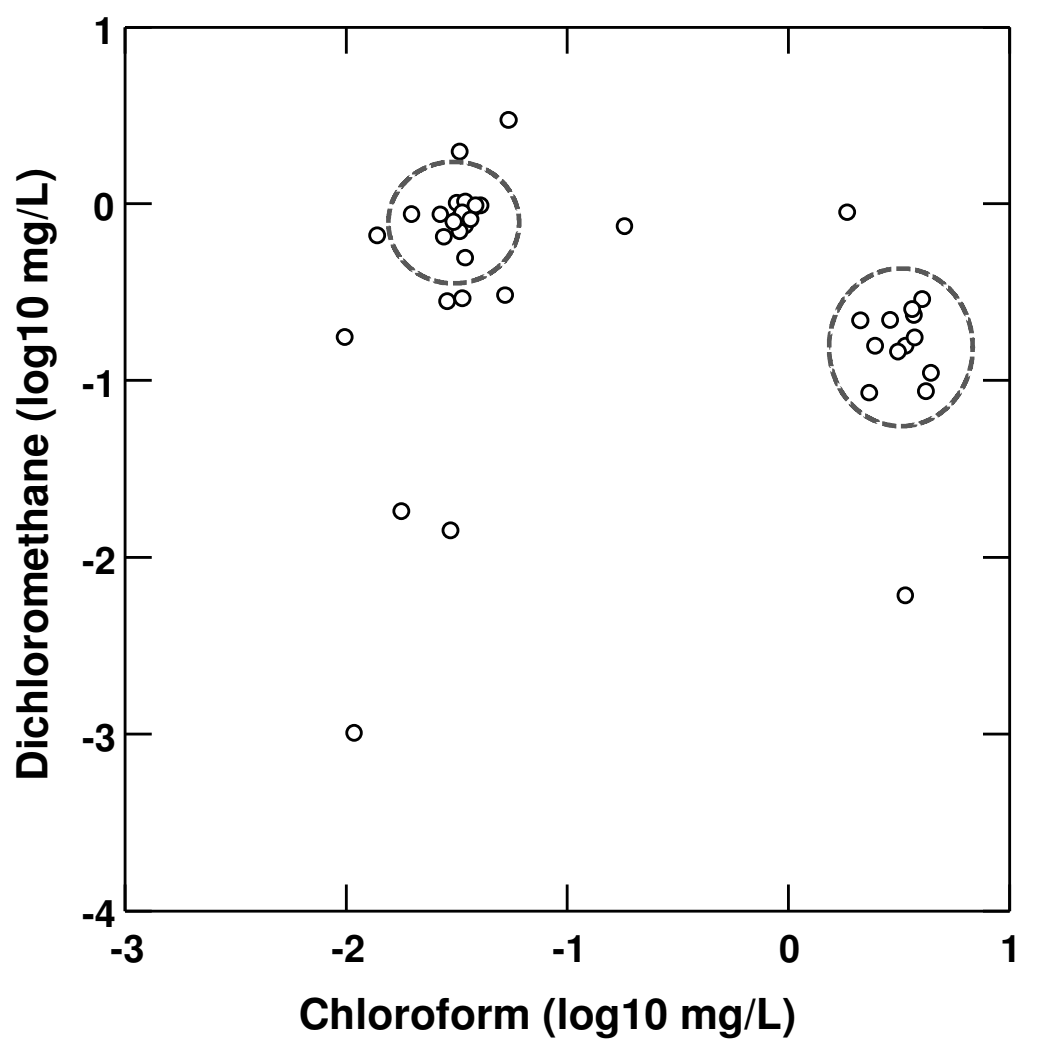

652 Figure 3. Dichloromethane concentrations in relation to chloroform concentrations in the 653 samples where the two constituents were both detected $(n=41)$.

654

655

656

657

658

659

660

661

662

663

664

665

666

667

668

669

670

671

672

673

674

675

676

677

678 
679 Table 1. Measures of general water quality variables as a function of distance from nearest 680 gas well (log meter) and depth of sample well (log meter), using multiple regression and 681 model selection (see text for details). Asterisks indicate that the 95\% confidence interval for 682 the slope parameter does not include zero. 683

\begin{tabular}{|l|l|l|l|l|}
\hline Variable & Best Model & Slope & $\boldsymbol{P}$-value & $\boldsymbol{R}^{2}$ adj \\
\hline $\log _{10}$-Temperature & $\begin{array}{l}\text { Dist + Depth }+ \\
\text { Dist }\end{array}$ & $\begin{array}{l}+0.04^{*} \\
\text { (interaction) }\end{array}$ & $<0.0001$ & 0.463 \\
\hline Log $_{10}$-DO & Depth & $-0.13^{*}$ & $<0.0001$ & 0.220 \\
\hline Log $_{10}$-Conductivity & Dist + depth & $\begin{array}{l}\text { Dist }=+0.03^{*} \\
\text { Depth }=+0.05^{*}\end{array}$ & $<0.0001$ & 0.125 \\
\hline $\log _{10}$-TDS & Dist + depth & $\begin{array}{l}\text { Dist }=+0.05^{*} \\
\text { Depth }=+0.03^{*}\end{array}$ & $<0.0001$ & 0.127 \\
\hline Log $_{10}-$ Salinity & Dist + Depth & $\begin{array}{l}\text { Dist }=+0.02^{*} \\
\text { Depth }=+0.05^{*}\end{array}$ & $\begin{array}{l}\text { Dist }=0.001 \\
\text { Depth }=<\end{array}$ & 0.096 \\
\hline Log $_{10}-\mathrm{pH}^{\#}$ & & 0.0001 & \\
\hline ORP & Depth & $+0.03^{*}$ & $<0.0001$ & 0.307 \\
\hline
\end{tabular}

684

\# Relationship is nonlinear; low $\mathrm{pH}$ at shallow depths, high $\mathrm{pH}$ at intermediate depths, and slight trend toward neutral $\mathrm{pH}$ at deepest depths ( $R^{2} \mathrm{adj}$ is based on linear approximation). 
707

708

709

710

711

712

713

714

715

716

717

718

726

727

728

719

720

721

722

723

724

725

Table 2. Pearson's chi-squared tests of independence for frequency of either detection ${ }^{1}$ or MCL exeedances ${ }^{2}$ of select compounds for counties with $\geq 40$ total samples. For significant tests, + and - symbols indicate whether observed detection and/or exceedance frequencies occurred more or less frequently than would be expected under the null hypothesis of dependence of observations. Compounds were selected based on whether expected frequencies were $>5$ for most cells, as recommended for contingency table analysis.

\begin{tabular}{|l|r|r|c|c|c|c|c|c|c|c|}
\hline & \multicolumn{1}{|c|}{$X^{2}$} & $p$ & $\begin{array}{c}\text { Cooke } \\
n=40\end{array}$ & $\begin{array}{c}\text { Denton } \\
n=82\end{array}$ & $\begin{array}{c}\text { Hood } \\
n=52\end{array}$ & $\begin{array}{c}\text { Johnson } \\
n=43\end{array}$ & $\begin{array}{c}\text { Montague } \\
n=66\end{array}$ & $\begin{array}{c}\text { Parker } \\
n=116\end{array}$ & $\begin{array}{c}\text { Tarrant } \\
n=47\end{array}$ & $\begin{array}{c}\text { Wise } \\
n=41\end{array}$ \\
\hline Methanol $^{1}$ & 2.75 & 0.908 & & & & & & & & \\
\hline Ethanol $^{1}$ & 80.1 & $<0.0001$ & - & - & - & - & + & + & + & + \\
\hline $\begin{array}{l}\text { Propargyl } \\
\text { Alcohol }^{1}\end{array}$ & 43.4 & $<0.0001$ & - & - & - & + & - & + & + & + \\
\hline DCM $^{2}$ & 93.3 & $<0.0001$ & - & - & + & + & - & + & - & - \\
\hline Chloroform $^{1}$ & 62.9 & $<0.0001$ & - & - & - & - & + & + & + & + \\
\hline Benzene $^{2}$ & 12.6 & 0.084 & & & & & & & & \\
\hline Cyclohexane $^{1}$ & 55.5 & $<0.0001$ & + & + & + & + & - & - & - & + \\
\hline Bromide $^{1}$ & 16.7 & 0.019 & - & - & - & - & + & + & - & + \\
\hline Beryllium $^{2}$ & 57.4 & $<0.0001$ & - & - & - & - & + & + & + & - \\
\hline Iron $^{2}$ & 37.6 & $<0.0001$ & + & - & - & + & + & - & - & - \\
\hline Molybdenum $^{2}$ & 118.0 & $<0.0001$ & - & - & - & - & + & + & - & + \\
\hline
\end{tabular}

\section{5}

16

17

18 


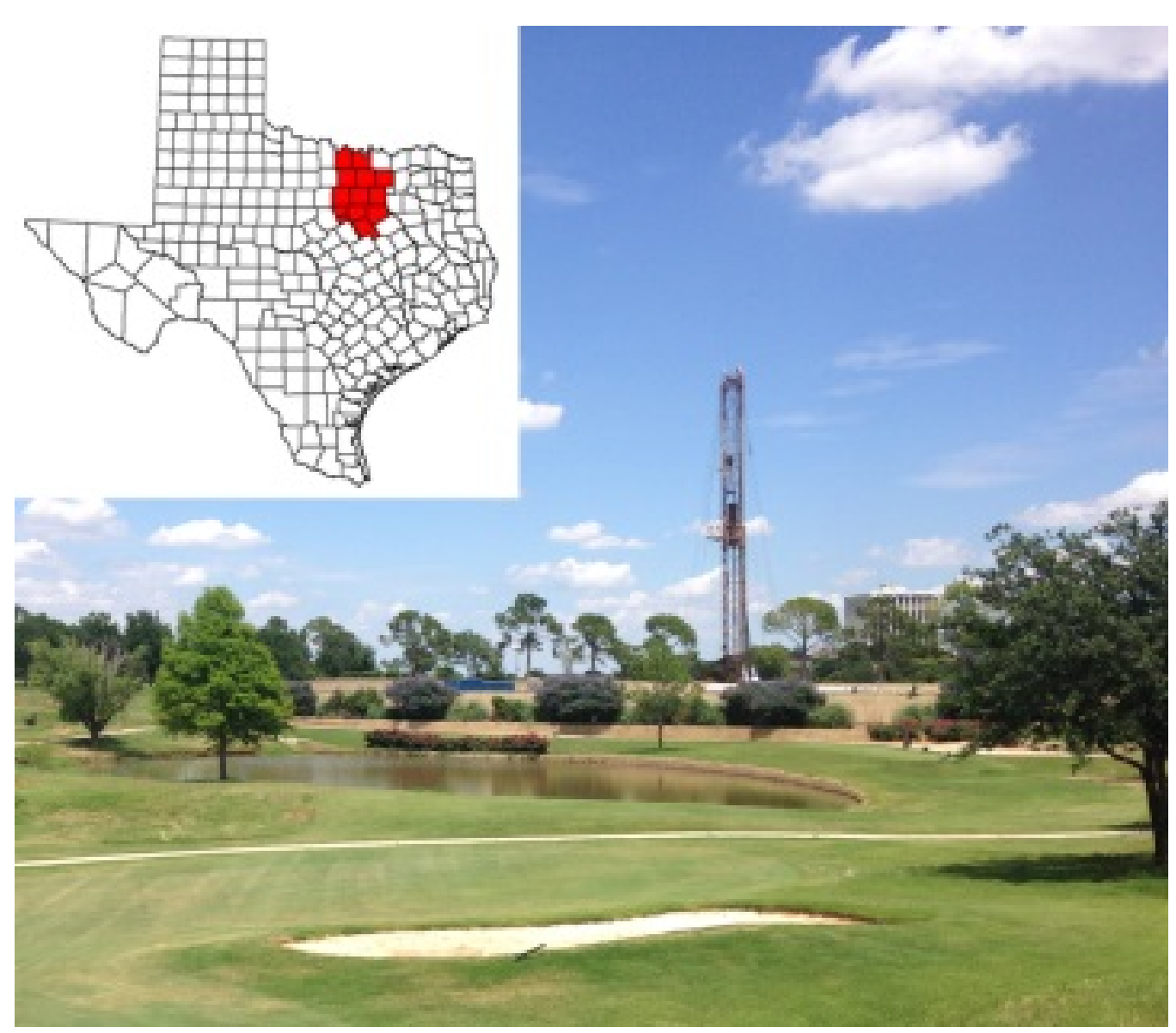

Photo credit: Doug D. Carlton, Jr. 